Article type: Original Research Article

\title{
Association Between Medication Adherence and the Outcomes of Heart Failure
}

Running Head: Medication Adherence and Heart Failure Outcomes

Sarah R. Hood ${ }^{1}$; Anthony J. Giazzon ${ }^{1}$; Gwen Seamon ${ }^{1}$; Kathleen A. Lane ${ }^{2}$; Jane Wang ${ }^{3}$; George J.

Eckert $^{2}$; Wanzhu Tu ${ }^{2}$ Michael D. Murray ${ }^{1,3}$

Author Affiliations: ${ }^{1}$ College of Pharmacy, Purdue University, West Lafayette. IN; ${ }^{2}$ Department of Biostatistics, Indiana University, Indianapolis, IN; ${ }^{3}$ Regenstrief Institute, Center of Health vices Bepearch, Indianapolis, IN

Primary Funding Source: Partially funded by the Regenstrief Foundation and Merck Corresponding Author: Michael D. Murray, 1101 W 10 ${ }^{\text {th }}$ St., Indianapolis, IN, 46202, USA, mdmurray@regenstrief.org, (317) 274-9181; FAX (317) 274-9304.

Disclosures: The authors have no financial or professional conflicts of interest to report. Keywords: heart failure; medication adherence; health outcomes; mortality; electronic medical records; health information exchange.

\section{Abstract}

Background: Previous studies of heart failure patients have demonstrated an association between cardiovascular medication adherence and hospitalizations or a composite end point of

This is the author's manuscript of the article published in final edited form as:

Hood, S. R., Giazzon, A. J., Seamon, G., Lane, K. A., Wang, J., Eckert, G. J., ... Murray, M. D. (n.d.). Association Between Medication Adherence and the Outcomes of Heart Failure. Pharmacotherapy: The Journal of Human Pharmacology and Drug Therapy. https://doi.org/10.1002/phar.2107 
hospitalization and death. Few studies have assessed the impact of treatment adherence within large general medical populations that distinguish the health outcomes of emergency department visits, hospitalization, and death.

Objective: To determine the association of incremental cardiovascular medication adherence on emergency department visits, hospitalization, and death in adult heart failure patients in Indiana.

Design: Retrospective cohort study conducted using electronic health record data from the statewide Indiana Network for Patient Care (INPC) between 2004 and 2009.

Methods: Patients were at least 18 years of age with a diagnosis of heart failure and prescribed at least one cardiovascular medication for heart failure. Adherence was measured as the proportion of days covered (PDC) using pharmacy transaction data. Clinical end points included emergency department visits, hospital admissions, length of hospital stay, and mortality. Generalized linear models were used to determine the effect of a $10 \%$ increase in PDC on clinical end points adjusting for age, sex, race, Charlson comorbidity index, and medications. Results: Electronic health records were available for 55,312 patients (mean age \pm standard deviation [SD] $68 \pm 16$ years; 54\% women; 65\% white). Mean PDC for all heart failure medications was $63 \% \pm 23 \%$. For every $10 \%$ increase in PDC, emergency department visits decreased $11 \%$ (rate ratio [RR] 0.89; 95\% confidence interval [CI] 0.89-0.89), hospital admissions decreased 6\% (RR 0.94; 95\% Cl 0.94-0.94), total length of hospital stay decreased 1\% (RR 0.99; 95\% Cl 0.99-1.00), and all-cause mortality decreased 9\% (odds ratio 0.91; $95 \% \mathrm{Cl}$ 0.90-0.92).

This article is protected by copyright. All rights reserved. 
Conclusion: Incremental medication adherence was associated with reductions in emergency department visits, hospital admissions, length of hospital stay, and all-cause mortality.

Chronic heart failure affects more than 6.5 million Americans and its prevalence may increase to more than 8 million Americans by $2030 .{ }^{1}$ It is a global disease, contributing to one in eight deaths and is increasing in areas where the risk factors for heart failure are common, such as in aging, ischemic heart disease, and hypertension. ${ }^{1}$ Patients diagnosed with heart failure are often prescribed multiple medications for which they have low treatment adherence resulting in poor health outcomes and costly care. ${ }^{2}$ Indeed, more than 500,000 heart failure-related hospitalizations occur each year with direct health care costs projected to reach $\$ 69.7$ billion in the United States by $2030 .{ }^{1}$ It is well documented that adherence to medication is a vital part of the self-care management of heart failure..$^{3-7}$ Notwithstanding, many heart failure patients fail to take their medications as prescribed at the risk of adverse health outcomes, ${ }^{8}$ including death. ${ }^{9}$ Interventions aimed at improving adherence to heart failure medications, however, reduce hospital readmissions and mortality. ${ }^{10}$

Many previous observational studies analyzing adherence had too few patients to examine an incremental effect of adherence on death or they focused mainly on patient characteristics rather than on health outcomes..$^{3-7,11}$ We identified multiple studies associating patient adherence to frequency of and time to clinical events such as cardiovascular ${ }^{7}$ or heart failure-related hospitalizations or a composite end point of these end points coupled with death. ${ }^{3,4,6,11}$ Studies of composite end points including death and those end points looking exclusively at hospitalizations had statistically significant results. However, these studies did not find a significant effect on death as an independent end point yet there were non-significant trends of an increased death rate with poor adherence. Our previous randomized trial of a pharmacist intervention aimed at improving adherence in heart failure patients had a favorable impact on emergency department visits and hospitalizations but had too few

This article is protected by copyright. All rights reserved. 
participants to assess the effects of adherence on mortality. ${ }^{12}$ We wanted to know whether the impact of improvements in treatment adherence translated to the broad population of patients in our state of Indiana so we conducted an observational study to determine the association between treatment adherence on health outcomes including urgent care, hospitalization, and death using data from a statewide health information exchange.

\section{Methods}

Patients

We extracted data from a health information exchange containing 55,312 patients with heart failure between January 1, 2004 and December 31, 2009. We included patients who were at least 18 years old, had an ICD9 code for heart failure (ICD9 codes $428 .{ }^{*}$ ), and were prescribed at least one outpatient cardiovascular medication with at least two prescription refills to treat heart failure during the study period. Heart failure medications considered included angiotensin-converting enzyme (ACE) inhibitors, angiotensin II receptor blockers (ARBs), beta-blockers, calcium-channel blockers, digoxin, diuretics, and the aldosterone antagonists, spironolactone or eplerenone. Prescription records were obtained from Surescripts ${ }^{\circledR}$, a pharmacy transaction processing network that connects greater than $90 \%$ of retail pharmacies in Indiana, during the study period. ${ }^{13}$

\section{Data Source}

Patients' digital health records were extracted from the Indiana Network for Patient Care (INPC). Most of the data extracted were coded elements. However, we attempted to obtain selected data such as functional health status using text mining of clinician notes within the health records. This health information exchange captures and stores digital health data across the state of Indiana including laboratory results, inpatient and outpatient encounter data (including urgent and emergent care), coded 
diagnoses and procedures, and digital prescription records among other information from the major health care systems in Indiana. ${ }^{14}$ The presence or absence of relevant comorbidities were derived from extracted ICD9 codes and physicians' problem lists for the patient and were used to calculate the Charlson Comorbidity Index for each patient. ${ }^{15}$ Generally, this interconnected health exchange is invaluable in reducing missing data from patients who receive their care from more than one health care system. However, we could only report on results that were accessible from these digital health records. For example, if a patient did not have a particular laboratory test, there would be no accessible result for that test to extract. Most of the data for the present study derived from Marion County and surrounding counties (greater Indianapolis). Death data are available from the Indiana State Department of Health and, at the time of the data extraction, were most accurate from 2004 to 2009. All data were de-identified prior to analysis. The Indiana University Purdue University of Indianapolis (IUPUI) Institutional Review Board granted approval for this study.

\section{Study Design}

This retrospective cohort study examined pharmacy transaction data for patients with heart failure to determine the percentage of days covered (PDC) as an estimate of their medication adherence. We used the method described by $\mathrm{Nau}^{16}$ with a time off-set as recommended by Bijlsma and colleagues. ${ }^{17}$ As proposed by Nau, we defined the PDC measurement frame as the date of the first/index prescription and the last date of the prescription plus the days covered with the last prescription or the last encounter in any one of the health systems of the INPC, or death. We then calculated the number of days by drugs in a specific class or overall drug classes. We then divided the number of days of drug coverage by the PDC measurement frame. We calculated the incremental adherence (in $10 \%$ increments) and examined the association of $10 \%$ increments on hospital admissions, number of emergency department visits, length of hospital stay, and all-cause mortality. 
Statistical Methods

Descriptive statistics including means and standard deviations for continuous data and counts and percentages for categorical data were calculated on patient characteristics and PDC usage. T-tests and one-way analysis of variance models were used to compare the PDC usage across patient characteristics.

A mixed effects model with a random subject effect was used to compare PDCs from various drug classes. A logistic regression model was used to determine the effect of a $10 \%$ PDC increase on mortality. Similarly, Poisson regression models were used on the remaining aforementioned outcomes. Models were adjusted for patient age, self-identified race, sex, number of cardiovascular medications, and Charlson comorbidity index. We specified a $\mathrm{p}$ value of less than 0.05 as statistically significant.

\section{Results}

Patient Characteristics

Participants included in the study were mostly older adults with an average (standard deviation [SD]) age of $68 \pm 16$ years old, women (54\%), and white (65\%) (Table 1). Patients were followed for a mean of $4.7 \pm 2.2$ years of observation and prescription history (the range was 0-41.4 years, median 4.7 years, and the interquartile range [IQR] was 2.8-6.6 years). The range of refills was 2 to 2582 with a mean of $151.4 \pm 155.8$. We found limited data within the digital clinical notes on patient functional health status as measured by clinicians using the New York Heart Association (NYHA) classification (only $2.1 \%$ of patients), which were Class I (22\%), II (37\%), III (31\%), or IV (10\%). Patients had a mean of $3.8 \pm 8.9$ emergency department visits, $7.8 \pm 14.1$ hospitalizations, and a mean cumulative number of hospital days of $36.4 \pm 108.4$ days (approximately 4.7 days per visit). There were $8515(15 \%)$ deaths in the study.

The mean PDC \pm SD for all medications was $63 \pm 23 \%$ and varied by self-identified race/ethnicity. The PDC was highest for non-Hispanic Whites (65\%), followed by Other race (60\%), non-Hispanic African 
Americans (57\%), and Hispanics (50\%) $(\mathrm{p}<0.0001)$. The mean PDC \pm SD was similar for men and women at $62.8 \pm 22.8 \%$ and $62.7 \pm 22.5 \%$, respectively ( $p=0.4916)$. Additionally, the PDC varied by type of cardiovascular medication taken as shown in Table 2. In particular, diuretics had lower PDCs than the ACE inhibitors, ARBs, and beta-blockers ( $p<0.0001$, controlling for multiple comparisons).

The multivariable model of the predictors of mortality including incremental changes in PDC is shown in Table 3. Notably, each $10 \%$ increase in overall PDC reduced the risk of death by $9 \%$ (odds ratio [OR], $0.91 ; 95 \%$ confidence interval $[\mathrm{Cl}], 0.90-0.92)$. Compared to males, females had a slightly increased risk of death (OR, 1.06; 95\% Cl, 1.00-1.11). While the difference in mortality between black and white patients was not statistically significant, patients within the Other category of race/ethnicity who selfidentified as Hispanic, Asian, Native American, Multiracial, or American Indian/Alaskan had a decreased risk of death compared with whites (OR, $0.45 ; 95 \% \mathrm{Cl}, 0.34-0.60)$. Age and comorbid conditions significantly increased the risk of death, but the numbers of cardiovascular drugs reduced this risk (OR, $0.84 ; 95 \% \mathrm{Cl}, 0.83-0.86)$.

As shown in Table 4, we found that improvements in adherence by $10 \%$ increments significantly reduced emergency department visits by $11 \%$ (rate ratio [RR], $0.89 ; 95 \% \mathrm{Cl}, 0.89-0.89$ ), hospital admissions by $6 \%(\mathrm{RR}, 0.94 ; 95 \% \mathrm{Cl}, 0.94-0.94)$, and total length of stay by $2 \%(\mathrm{RR}, 0.99 ; 95 \% \mathrm{Cl}, 0.99$ 1.00). All utilization outcomes were statistically significant $(p<0.0001)$. Compared with males, females had a greater RR for emergency department visits but a lower rate of hospitalizations and length of stay. Black and Other race had greater RRs than whites for emergency department visits, hospitalizations, and corresponding length of stay. In contrast to the reduced odds of death with greater numbers of cardiovascular drugs, the rate of utilization outcomes was greater as the number of cardiovascular drugs increased.

This article is protected by copyright. All rights reserved. 


\section{Discussion}

Our results suggest that increasing adherence to heart failure medications measured as a $10 \%$ increment has a favorable effect on health outcomes including reducing mortality by $9 \%(O R, 0.91 ; 95 \%$ $\mathrm{Cl}, 0.90-0.92$ ). We were particularly interested in the effects of adherence on mortality because there were few studies available that investigated such effects in patients with heart failure from the clinical setting. The association of cardiovascular drug adherence on health utilization in the present study generally agree with our previous study of a pharmacy intervention to improve adherence but the intervention study had too few participants to assess an effect of adherence on mortality. Nonetheless, data from randomized controlled drug trials, ${ }^{18,19}$ a systematic review of interventions to improve adherence in patients with heart failure, ${ }^{10}$ and one international registry study ${ }^{20}$ would suggest an effect of treatment adherence on mortality. In the clinical setting, two key aspects are important: 1) physician prescribing evidence-based medications, and 2) patients taking their medications as prescribed. For clinicians, the widely accepted notion that treating heart failure to a targeted dosing goal is an effective way of improving outcomes, including reducing mortality; ${ }^{21}$ however, prescribers may not always follow recommended guidelines. ${ }^{22-24}$ Notwithstanding, even when clinicians follow evidence-based guidelines, health outcomes will not improve for patients who do not adhere to the therapy they have been prescribed.

Adherence to medication is associated with improved health outcomes including mortality, ${ }^{3-7}$ but our study is among the first to look at electronic medical record data from a health information exchange in a large, longitudinal cohort of heart failure patients from general medical settings $(\mathrm{N}=55,312)$. We observed effects on age, sex, race, and comorbidity that we controlled for in the assessment of effects on health outcomes. Female patients had a slightly greater risk of death than males, which may be related to a less attention to cardiovascular risk factors ${ }^{25}$ and lower prescribing of effective medications in women than in men. ${ }^{26}$ The effects of race on mortality and utilization outcomes 
could be the result of variation in cardiovascular medication prescribing to racial and ethnic minorities and their adherence to treatments. ${ }^{8,27}$

Class of medication has been linked to adherence rates in previous studies, specifically diuretics showing lower and beta-blockers showing higher adherence rates. ${ }^{28}$ In contrast, patients taking statins, anticoagulants, antiarrhythmics, or fixed-dose combination products tended to have better adherence rates. ${ }^{28}$ Consistent with these studies, we found lower adherence to diuretics compared with the other heart failure medications including beta-blockers. Adverse events such as increased urinary frequency with subsequent limits on patient mobility are also a possible explanation for patients not adhering to diuretics. Overall, our study also suggests a beneficial effect of cardiovascular medications in patients with heart failure from general clinical settings.

There are limitations to our study that are pertinent to address. Because we used predominantly coded digital data from the health information exchange, we were unable to control for important lifestyle effects such as diet and exercise, which could have a great impact on outcomes. Indeed, medication adherence may also be associated with adherence to a healthy lifestyle that would also improve outcomes. In a randomized controlled study of candesartan, even patients who did not receive active therapy had improved health outcomes with higher adherence to placebo. ${ }^{18}$ Thus, adherence to medication therapy may be indicative of general "adherent behavior" in which patients also adhere to lifestyle advice. ${ }^{3,18}$ Adherence is also influenced by levels of social support, comorbid conditions such as depression and dementia, and patients' perceptions of the importance of taking medication..$^{5-7,29-31}$ Cognitive impairment is also a determinant of adherence and poor outcomes; ${ }^{32}$ however, we did not have access to data on patient cognitive status. Our results included data for the period of 2004 to 2009 because our death data were valid and reconciled for this period. As such, newer drugs that have been shown to improve heart failure outcomes, such as sacubitril/valsartan and ivabradine, were not part of our adherence analysis. These drugs are slowly becoming an integral part 
of heart failure treatment and future studies should examine how adherence affects outcomes with these medications. ${ }^{33}$ It is also important to note that the PDC as a measure of adherence does not confirm that patients actually took their medications. Instead, the PDC only affirms medications were obtained from the pharmacy, suggesting that they were taken as prescribed. Finally, while the health information exchange allowed us to limit data that would otherwise be missing for patients visiting more than a single health system, we had limited data on NYHA classification, which was poorly documented in patients' clinical notes. Nonetheless, the limited data on NYHA class would not affect our primary results involving incremental changes in medication adherence and important health outcomes in patients with heart failure.

We conclude that incrementally increasing medication adherence reduces the risk of negative outcomes including death, emergency department visits, hospitalization, and length of hospital stay in heart failure patients. Our findings stress the importance of clinicians' active attention to improving adherence and thinking of adherence as a necessary component of effective pharmacotherapy.

\section{Acknowledgments}

The authors wish to thank Veronica Bonderski and Rachel Gruber for their kind review of this manuscript and for their suggestions.

\section{References}

1. Benjamin EJ, Blaha MJ, Chiuve SE, et al. Heart disease and stroke statistics-2017 update: a report from the American Heart Association. Circulation 2017;135(10):e146-e603.

2. Taylor $\mathrm{CJ}$, Valenti L, Britt $\mathrm{H}$, et al. Management of chronic heart failure in general practice in Australia. Aust Fam Physician 2016;45(11):734-9.

This article is protected by copyright. All rights reserved. 
3. Granger BB. Self-reported medication adherence for heart failure is associated with lower risk of all-cause hospitalisation and death. Evidence-Based Nursing 2015;18:123.

4. Wu JR, DeWalt DA, Baker DW, et al. A single-item self-report medication adherence question predicts hospitalisation and death in patients with heart failure. J Clin Nurs 2014;23(1718):2554-64.

5. Wu J-R, Lennie TA, Dekker RL, Biddle MJ, Moser DK. Medication adherence, depressive symptoms, and cardiac event-free survival in patients with heart failure. J Card Fail 2013;19(5):317-24.

6. Wu JR, Frazier SK, Rayens MK, Lennie TA, Chung ML, Moser DK. Medication adherence, social support, and event-free survival in patients with heart failure. Health Psychol 2013;32(6):637-46.

7. Heisler $\mathrm{M}$, Choi $\mathrm{H}$, Rosen $\mathrm{AB}$, et al. Hospitalizations and deaths among adults with cardiovascular disease who underuse medications because of cost: a longitudinal analysis. Med Care 2010;48(2):87-94.

8. Zhang Y, Wu SH, Fendrick AM, Baicker K. Variation in medication adherence in heart failure. JAMA Intern Med 2013;173(6):468-70.

9. Simpson SH, Eurich DT, Majumdar SR, et al. A meta-analysis of the association between adherence to drug therapy and mortality. BMJ 2006;333(7557):15.

10. Ruppar TM, Cooper PS, Mehr DR, Delgado JM, Dunbar-Jacob JM. Medication adherence interventions improve heart failure mortality and readmission rates: systematic review and meta-analysis of controlled trials. J Am Heart Assoc 2016;5(6):e002606.

11. Nelson MR, Reid CM, Ryan P, Willson K, Yelland L. Self-reported adherence with medication and cardiovascular disease outcomes in the Second Australian National Blood Pressure Study (ANBP2). Med J Aust 2006;185(9):487-9.

This article is protected by copyright. All rights reserved. 
12. Murray MD, Young J, Hoke S, et al. Pharmacist intervention to improve medication adherence in heart failure: a randomized trial. Ann Intern Med 2007;146(10):714-25.

13. Pharmacies connected to Surescripts. Network Connections. Available from http://surescripts.com/network-connections/connected-pharmacies/. Accessed March 5, 2018.

14. McDonald CJ, Overhage JM, Barnes M, et al. The Indiana network for patient care: a working local health information infrastructure. An example of a working infrastructure collaboration that links data from five health systems and hundreds of millions of entries. Health Aff (Millwood) 2005;24(5):1214-20.

15. Charlson M, Szatrowski TP, Peterson J, Gold J. Validation of a combined comorbidity index. J Clin Epidemiol 1994;47(11):1245-51.

16. Nau DP. Proportion of days covered (PDC) as a preferred method of measuring medication adherence. Springfield, VA: Pharmacy Quality Alliance, 2012.

17. Bijlsma MJ, Janssen F, Hak E. Estimating time-varying drug adherence using electronic records: extending the proportion of days covered (PDC) method. Pharmacoepidemiol Drug Saf 2016;25(3):325-32.

18. Granger BB, Swedberg K, Ekman I, et al. Adherence to candesartan and placebo and outcomes in chronic heart failure in the CHARM programme: double-blind, randomised, controlled clinical trial. Lancet 2005;366(9502):2005-11.

19. Bohm M, Schumacher H, Laufs U, et al. Effects of nonpersistence with medication on outcomes in high-risk patients with cardiovascular disease. Am Heart J 2013;166(2):306-14.e7.

20. Komajda M, Cowie MR, Tavazzi L, Ponikowski P, Anker SD, Filippatos GS. Physicians' guideline adherence is associated with better prognosis in outpatients with heart failure with reduced ejection fraction: the QUALIFY international registry. Eur J Heart Fail 2017;19(11):1414-23.

This article is protected by copyright. All rights reserved. 
21. Yancy CW, Jessup M, Bozkurt B, et al. 2013 ACCF/AHA guideline for the management of heart failure: a report of the American College of Cardiology Foundation/American Heart Association Task Force on Practice Guidelines. J Am Coll Cardiol 2013;62(16):e147-e239.

22. Rodgers JE, Stough WG. Underutilization of evidence-based therapies in heart failure: the pharmacist's role. Pharmacotherapy. 2007;27(4 Pt 2):18S-28S..

23. Chin KL, Skiba M, Tonkin A, et al. The treatment gap in patients with chronic systolic heart failure: a systematic review of evidence-based prescribing in practice. Heart Fail Rev 2016;21(6):675-97.

24. Poelzl G, Altenberger J, Pacher R, et al. Dose matters! Optimisation of guideline adherence is associated with lower mortality in stable patients with chronic heart failure. Int J Cardiol 2014;175(1):83-9.

25. Hyun KK, Redfern J, Patel A, et al. Gender inequalities in cardiovascular risk factor assessment and management in primary healthcare. Heart 2017;103:492-8.

26. Tran HV, Waring ME, McManus DD, et al. Underuse of effective cardiac medications among women, middle-aged adults, and racial/ethnic minorities with coronary artery disease (from the National Health and Nutrition Examination Survey 2005 to 2014). Am J Cardiol 2017;120(8):1223-9.

27. Cuffee YL, Hargraves JL, Rosal M, et al. Reported racial discrimination, trust in physicians, and medication adherence among inner-city African Americans with hypertension. Am J Public Health. 2013;103(11):e55-e62.

28. Schulz M, Krueger K, Schuessel K, et al. Medication adherence and persistence according to different antihypertensive drug classes: a retrospective cohort study of 255,500 patients. Int J Cardiol 2016;220:668-76.

This article is protected by copyright. All rights reserved. 
29. Wu JR, Lennie TA, Chung ML, et al. Medication adherence mediates the relationship between marital status and cardiac event-free survival in patients with heart failure. Heart Lung 2012;41(2):107-14.

30. Buja A, Solinas G, Visca M, et al. Prevalence of heart failure and adherence to process indicators: Which socio-demographic determinants are involved? Int J Environ Res Public Health. $2016 ; 13(2): 238$.

31. Granger BB, Ekman I, Hernandez AF, et al. Results of the Chronic Heart Failure Intervention to Improve MEdication Adherence study: a randomized intervention in high-risk patients. Am Heart J 2015;169(4):539-48.

32. Howell EH, Senapati A, Hsich E, Gorodeski EZ. Medication self-management skills and cognitive impairment in older adults hospitalized for heart failure: a cross-sectional study. SAGE Open Med 2017;5:2050312117700301.

33. Adams KF, Jr., Giblin EM, Pearce N, Patterson JH. Integrating new pharmacologic agents into heart failure care: role of heart failure practice guidelines in meeting this challenge. Pharmacotherapy. 2017;37(6):645-56.

This article is protected by copyright. All rights reserved. 
Table 1. Patient Characteristics

\begin{tabular}{|c|c|c|}
\hline Characteristic & $\begin{array}{l}\text { No. of Patients with } \\
\text { Available Baseline Data }\end{array}$ & Mean \pm SD or Frequency (\%) \\
\hline Number of patients, $\mathrm{N}$ & 55,312 & - \\
\hline Mean age, years \pm SD & 55,312 & $67.7 \pm 16.1$ \\
\hline Sex, n (\%) & 55,312 & \\
\hline Female & & $29,528(54)$ \\
\hline Male & & $25,784(46)$ \\
\hline Race, n (\%) & 46,644 & \\
\hline White & & $36,245(65)$ \\
\hline Black & & $9766(18)$ \\
\hline Other & & $375(0.68)$ \\
\hline Hispanic & & $259(0.47)$ \\
\hline NYHA classification, $\mathrm{n}(\%)$ & 1153 & \\
\hline I & & $253(22)$ \\
\hline II & & $429(37)$ \\
\hline III & & $355(31)$ \\
\hline IV & & $116(10)$ \\
\hline Comorbidites, n (\%) & 55,102 & \\
\hline Hypertension & & $43,156(78)$ \\
\hline Diabetes & & $23,054(41)$ \\
\hline Chronic kidney disease & & $11,661(21)$ \\
\hline Coronary artery disease & & $29,788(54)$ \\
\hline Myocardial infarction & & $10,994(20)$ \\
\hline Hyperlipidemia & & $28,712(52)$ \\
\hline Atrial fibrilation & & $13,978(25)$ \\
\hline Stroke & & $5000(9)$ \\
\hline Chronic obstructive pulmonary disease & & $17,803(32)$ \\
\hline
\end{tabular}

This article is protected by copyright. All rights reserved. 


\begin{tabular}{|l|l|l|}
\hline Depression & \multicolumn{2}{|l|}{$8398(15)$} \\
\hline Laboratory tests, mean \pm SD & \multicolumn{2}{|l|}{} \\
\hline Mean ejection fraction & 10,759 & $50.9 \pm 14$ \\
\hline Mean pro-BNP level & 20,790 & $563.9 \pm 851$ \\
\hline Mean body weight & 14,252 & $202.9 \pm 64$ \\
\hline Mean systolic blood pressure ${ }^{\mathrm{a}}$ & 6979 & $133.3 \pm 18$ \\
\hline Mean diastolic blood pressure ${ }^{\mathrm{a}}$ & 6978 & $74.7 \pm 11$ \\
\hline Mean hematocrit & 34,778 & $36 \pm 14$ \\
\hline Mean serum creatinine level & 35,281 & $1.4 \pm 1.3$ \\
\hline
\end{tabular}

BNP = brain natriuretic peptide; NYHA = New York Heart Association; SD = standard deviation.

${ }^{a}$ Blood pressure measurements were the mean of clinic measurements while patients were sitting.

This article is protected by copyright. All rights reserved. 
Table 2. Mean PDC by Drug Class

\begin{tabular}{lll}
\hline Drug Class & $\mathbf{N}(\%)$ & Mean PDC, $\mathbf{\text { P SD }} \mathbf{a}^{\mathbf{a}}$ \\
\hline Overall & -- & $63 \pm 23$ \\
\hline ACE inhibitor & $30,599(55)$ & $63 \pm 30$ \\
\hline Anticoagulant & $14,035(25)$ & $59 \pm 30$ \\
\hline ARB & $14,368(26)$ & $65 \pm 29$ \\
\hline Aspirin/Antiplatelet & $14,587(26)$ & $60 \pm 32$ \\
\hline Beta-blocker & $38,461(70)$ & $64 \pm 28$ \\
\hline Any calcium channel blocker & $21,613(39)$ & $63 \pm 30$ \\
\hline Digoxin & $7368(13)$ & $63 \pm 31$ \\
\hline Loop diuretic & $31,308(57)$ & $56 \pm 31$ \\
\hline Potassium-sparing diuretic & $3366(6)$ & $54 \pm 33$ \\
\hline Statin & $34,273(62)$ & $66 \pm 28$ \\
\hline Thiazide diuretic & $17,689(32)$ & $54 \pm 32$ \\
\hline Any diuretic & $39,733(72)$ & $60 \pm 29$ \\
\hline
\end{tabular}

$\mathrm{ACE}=$ angiotensin-converting enzyme; $\mathrm{ARB}=$ angiotensin receptor blocker; $\mathrm{PDC}=$ proportion of days covered; SD = standard deviation.

${ }^{\mathrm{a} A}$ model comparing all drug classes excluding the overall has a $\mathrm{p}<0.0001$.

This article is protected by copyright. All rights reserved. 
Table 3. Results from Logistic Regression Model of All-Cause Mortality in Heart Failure Patients

\begin{tabular}{llll}
\hline Category & Odds Ratio & $95 \% \mathrm{Cl}$ & P value \\
\hline $10 \%$ PDC increase & 0.91 & $0.90-0.92$ & $<.0001$ \\
\hline Gender (female vs. male) & 1.06 & $1.00-1.11$ & 0.0367 \\
\hline Race - overall ${ }^{\mathrm{a}}$ & -- & -- & $<.0001$ \\
\hline Black vs. white & 1.00 & $0.94-1.07$ & 0.9918 \\
\hline Other ${ }^{\text {val }}$ white & 0.45 & $0.34-0.60$ & $<.0001$ \\
\hline Age at index & 1.00 & $0.99-1.00$ & $<.0001$ \\
\hline Number of cardiovascular drugs & 0.84 & $0.83-0.86$ & $<.0001$ \\
\hline Charlson Comorbidity Index & 1.25 & $1.23-1.26$ & \\
\hline
\end{tabular}

$\mathrm{Cl}=$ confidence interval; PDC $=$ proportion of days covered.

${ }^{a}$ Other race includes the following number of individuals who self-identified their race as Hispanic (259), Other (255), Asian (102), Native American (11), Multiracial (3), and American Indian/Alaskan (2).

This article is protected by copyright. All rights reserved. 
Table 4. Results from Poisson Regression Models of Health Care Utilization in Heart Failure Patients

\begin{tabular}{|c|c|c|c|}
\hline Category & Rate Ratio & $95 \% \mathrm{Cl}$ & $P$ value \\
\hline \multicolumn{4}{|l|}{ Emergency Department Visits } \\
\hline $10 \%$ PDC increase & 0.89 & $0.89-0.89$ & $<.0001$ \\
\hline Age at index & 0.99 & 0.99-0.99 & $<.0001$ \\
\hline Gender (female) & 1.04 & $1.03-1.05$ & $<.0001$ \\
\hline Gender (male) & 1.00 & $1.00-1.00$ & - \\
\hline Race (Black) & 1.28 & $1.27-1.29$ & $<.0001$ \\
\hline Race $\left(\right.$ Other $^{\mathrm{a}}$ ) & 1.12 & $1.08-1.16$ & $<.0001$ \\
\hline Race (White) & 1.00 & $1.00-1.00$ & - \\
\hline Number of cardiovascular drugs & 1.02 & $1.02-1.02$ & $<.0001$ \\
\hline Charlson Comorbidity Index & 1.13 & $1.13-1.14$ & $<.0001$ \\
\hline \multicolumn{4}{|l|}{ Hospital Admissions } \\
\hline $10 \%$ PDC increase & 0.94 & $0.94-0.94$ & $<.0001$ \\
\hline Age at index & 1.00 & $1.00-1.00$ & 0.0019 \\
\hline Gender (female) & 0.97 & $0.97-0.98$ & $<.0001$ \\
\hline Gender (male) & 1.00 & $1.00-1.00$ & - \\
\hline Race (Black) & 0.77 & $0.76-0.78$ & $<.0001$ \\
\hline Race $\left(\right.$ Other $^{\mathrm{a}}$ ) & 0.93 & $0.91-0.96$ & $<.0001$ \\
\hline Race (White) & 1.00 & $1.00-1.00$ & - \\
\hline Number of cardiovascular drugs & 1.01 & $1.01-1.01$ & $<.0001$ \\
\hline Charlson Comorbidity Index & 1.20 & $1.20-1.20$ & $<.0001$ \\
\hline \multicolumn{4}{|l|}{ Length of Hospital Stay, days } \\
\hline $10 \%$ PDC increase & 0.99 & $0.99-1.00$ & $<.0001$ \\
\hline Age at index & 1.00 & $1.00-1.00$ & $<.0001$ \\
\hline Gender (female) & 0.97 & $0.96-0.97$ & $<.0001$ \\
\hline Gender (male) & 1.00 & $1.00-1.00$ & - \\
\hline
\end{tabular}

This article is protected by copyright. All rights reserved. 


\begin{tabular}{lccc}
\hline Category & Rate Ratio & $95 \% \mathrm{Cl}$ & P value \\
\hline Race (Black) & 1.10 & $1.10-1.10$ & $<.0001$ \\
\hline Race (Other ${ }^{\mathrm{a}}$ ) & 1.05 & $1.03-1.06$ & $<.0001$ \\
\hline Race (White) & 1.00 & $1.00-1.00$ & $<$ \\
\hline Number of cardiovascular drugs & 1.02 & $1.02-1.02$ & $<.0001$ \\
\hline Charlson Comorbidity Index & 1.15 & $1.15-1.15$ & $<.0001$ \\
\hline Cl = confidence interval; PDC = proportion of days covered. &
\end{tabular}

${ }^{a}$ Other race includes the following number of individuals who self-identified their race as Hispanic (259), Other (255), Asian (102), Native American (11), Multiracial (3), and American Indian/Alaskan (2).

This article is protected by copyright. All rights reserved. 